\title{
Towards Li Quantification at High Spatial Resolution Using EDS
}

\author{
P. Hovington ${ }^{1}$, V. Timoshevskii ${ }^{1}$, S. Burgess ${ }^{2}$, P. Statham ${ }^{2}$, H. Demers ${ }^{3}$, R. Gauvin ${ }^{3}$, K. Zaghib ${ }^{1}$ \\ ${ }^{1 .}$ Hydro-Quebec Reaserch Institute, Varennes, Quebec, Canada \\ 2. Oxford Instruments NanoAnalysis, High Wycombe UK. \\ 3. Department of Mining and Materials Engineering, McGill University, Montreal, Quebec, Canada.
}

Lithium is one of the most important elements that is still very difficult to localised and quantified in an electron microscope. Most battery technology is based on the displacement of Lithium ion $\left(\mathrm{Li}^{+}\right)$from two active materials (i.e., graphite for the anode and $\mathrm{LiFePO}_{4}$ for the cathode). It is thus essential to determine the distribution and the amount of Li with a good spatial resolution $(<<1 \mu \mathrm{m})$. In terms of local chemical analysis, Li is very difficult to analyze using conventional detectors because it emits very low-energy characteristic X-rays $(54 \mathrm{eV})$. Theoretical calculation and experimental detection of Li K X-rays for several lithium binary materials using EDS has recently been reported [1]. However, capability will be significantly enhanced if quantitative measurement can be demonstrated. We have seen a discrepancy in the predicted and measured emission of some lithium compounds and we are currently investigating the particular emission mechanism of some materials in order to be able to quantify Li using the Li K X-ray emission.

We present in table 1 the experimental and Monte Carlo simulation Li K k-ratio (vs Li K from metallic Li taken at $5 \mathrm{kV}$ ). Despite the number of unknowns, the difference between the experimental Li K k-ratio and Monte Carlo prediction is often within a factor of 3 . One compound that is showing a very high discrepancy is LiF (Li K-ratio of 18.3). Figure 1 is showing a spectrum on $\mathrm{LiF}$ taken using a spot mode compared to a spectrum taken in image mode. All spectra were taken at $2 \mathrm{kV}$ using the same beam current (1nA) and the same live time (30 sec). We clearly see that the spectrum taken in spot mode contains a much higher Li K signal and a much lower F K peak than the one taken using the area mode. Figure 1 is also showing severe beam damage after the spot mode acquisition (30 secs). During acquisition in spot mode, we also noted that the increase of Li intensity with time is always accompanied by a decrease of $F$.

In order to confirm that $\mathrm{Li}$ and $\mathrm{F}$ can be sputtered using electron beam, we used a time of flight secondary ions mass detector (TOF-SIMS) installed in our FIB-SEM (Tescan Lyra3). However, during this experiment, no primary ion beam is used so the secondary ions are created using the electron beam. We clearly see, in the mass spectrum presented in Figure 2, a $\mathrm{Li}+$ and $\mathrm{F}+$ peak. This clearly demonstrated the sputtering of both species and the ionization of the ejected $\mathrm{F}$ by the electron beam at this current $(1 \mathrm{nA})$. We expect the effect to increase with increasing beam current and would therefore be even more noticeable with the new grating system [2] where currents of at least 10nA have been employed. This experiment clearly shows that the emission is a function of electrons dose and is not constant with time. It is needless to say that these phenomena are not taken into account in a standard X-ray quantification program. Quantitative X-ray techniques are based on the premise that the number of generated X-rays is directly related to the composition in the analyzed compound (no chemical bonding effect) and varies linearly with current. These criteria are not met for LiF. Therefore new quantification schemes that include chemical effects and controlled incident beam exposure will have to be developed for this type of material.

In conclusion, the used of detectors capable of detecting $\mathrm{Li}$ in compounds in the SEM is promising for $\mathrm{Li}$ detection with good spatial resolution. However, new quantification scheme based on prior knowledge of the emission of the line of interest, including the effect of chemical bonding, will have to be developed.

\section{References}

[1] P. Hovington et al, Scanning 2016, in press

[2] M. Terauchi et al, Journal of Electron Microscopy 61(1) (2012), p. 1. 


\begin{tabular}{|l|l|r|r|r|}
\hline $\begin{array}{l}\text { Compound } \\
\text { Formula }\end{array}$ & $\begin{array}{l}\text { Li } \\
\text { (wt } \\
\text { \%) }\end{array}$ & $\begin{array}{l}\text { Li K- } \\
\text { ratio } \\
\text { Exp }\end{array}$ & $\begin{array}{l}\text { Li K- } \\
\text { ratio } \\
\text { MC }\end{array}$ & $\begin{array}{l}\text { Li K-ratio } \\
\text { Exp/MC }\end{array}$ \\
\hline $\begin{array}{l}\text { Li film } \\
(5 \mathrm{kV})\end{array}$ & 100 & 1.0 & 1.0 & 1.0 \\
\hline $\mathrm{LiH}(5 \mathrm{kv})$ & 87.3 & 0.3 & 0.5 & 0.5 \\
\hline $\mathrm{Li}_{3} \mathrm{~N}(5 \mathrm{kv})$ & 59.8 & 0.3 & 0.1 & 2.9 \\
\hline $\mathrm{Li}_{2} \mathrm{~S}(5 \mathrm{kv})$ & 30.2 & 0.4 & 0.3 & 1.2 \\
\hline $\mathrm{LiF}(2 \mathrm{kV})$ & $\mathbf{2 6 . 8}$ & 0.9 & 0.0 & 18.3 \\
\hline
\end{tabular}

Table 1. Li K-ratio (vs, metallic Li @ $5 \mathrm{kV}$ ) for both experimental and MC simulations of several Li compounds[1]
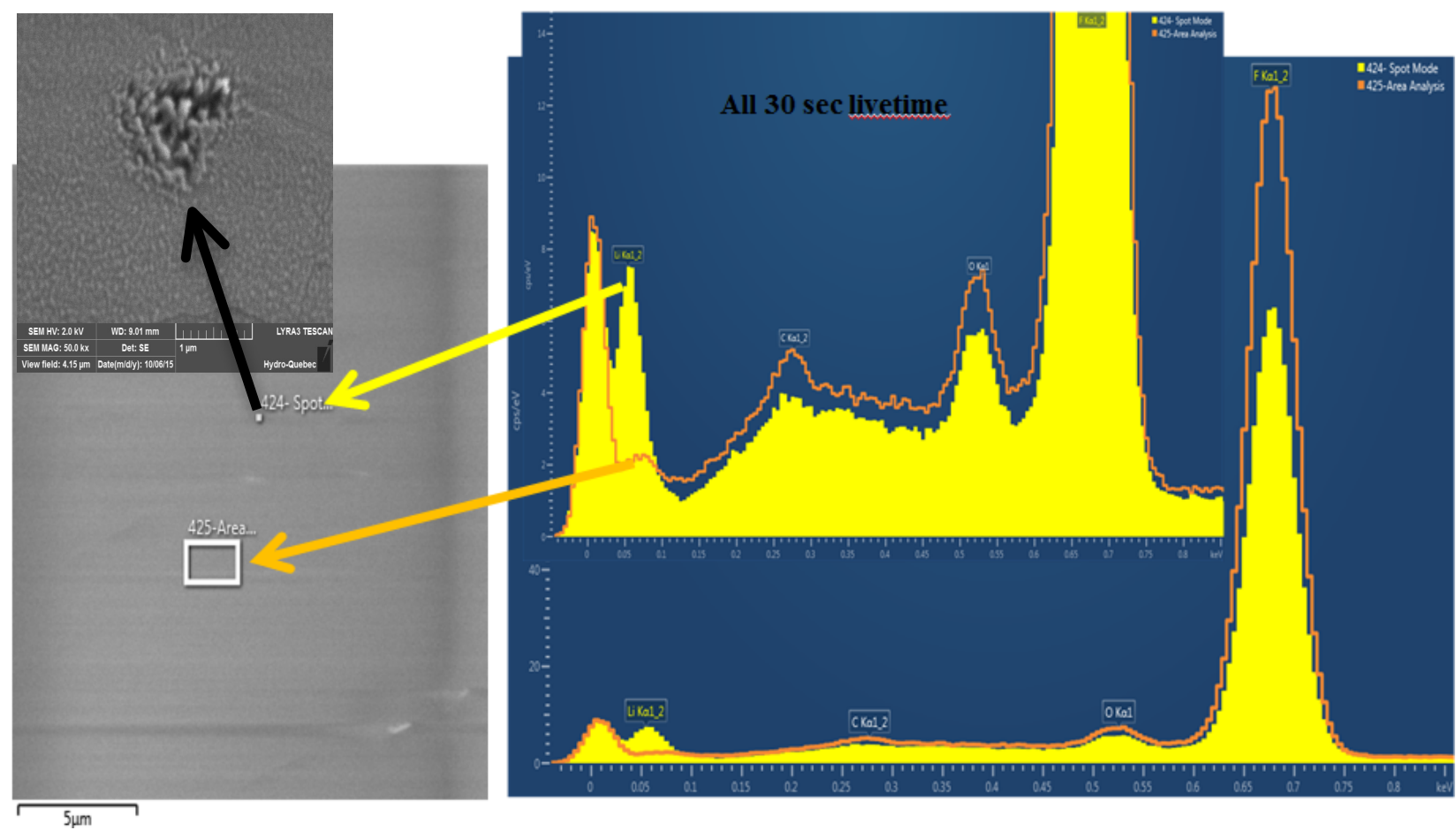

Figure 1. EDS X-Ray spectra on LiF taken at $2 \mathrm{kv}(1 \mathrm{nA})$ in spot and area mode. Also shown, a higher magnification micrograph of the region after acquisition in spot mode showing severe beam damage.

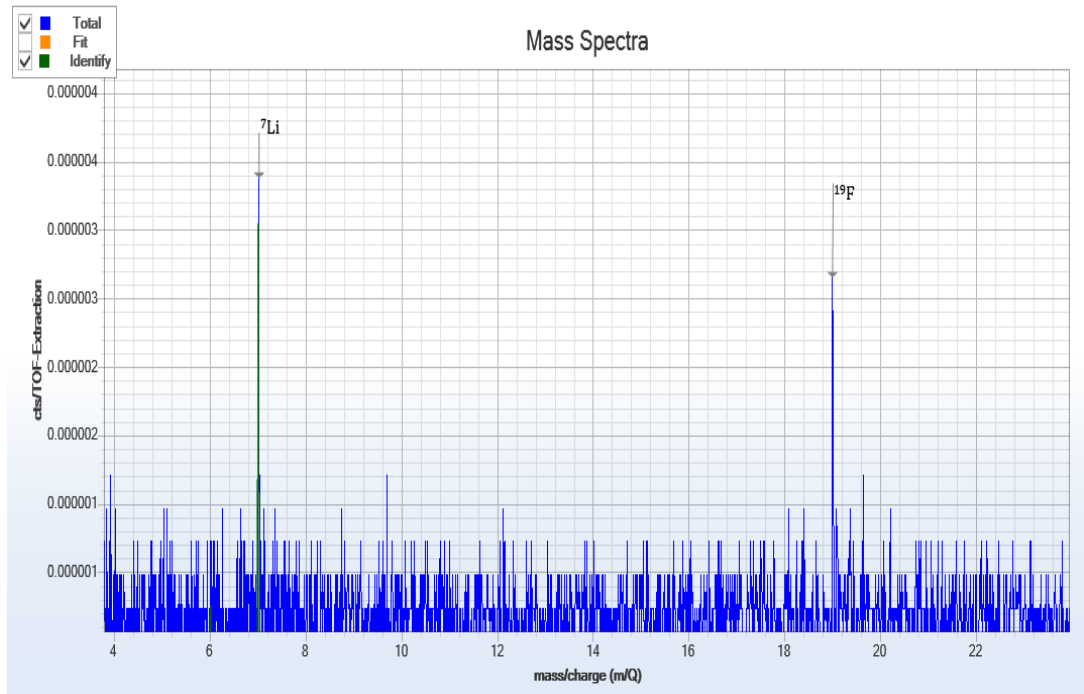

Figure 2. Mass spectra of electrons sputtered [7]Li+ and [19] F+ during EDS analysis in spot mode. No primary ion was used. 